\title{
Strategic Modulation of the Photonic Properties of Conjugated Organometallic Pt-Ir Polymers Exhibiting Hybrid CT Excited States
}

\author{
Ahmed M. Soliman, Eli Zysman-Colman* ${ }^{\dagger}$ and Pierre D. Harvey*
}

Contribution from the Département de chimie, Université de Sherbrooke, Sherbrooke, Québec, Canada J1K 2R1.

Correspondence: Pierre D. Harvey, email: Pierre.Harvey@USherbrooke.ca and Eli Zysman-Colman, email: eli.zysman-colman@st-andrews.ac.uk

${ }^{\dagger}$ Current address: EaStCHEM School of Chemistry, Rm 254, Purdie Building, North Haugh University of St. Andrews, St Andrews, Fife, UK KY16 9ST. URL: www.zysman-colman.com

Contribution for the special issue on Metallo-polymers (guest editors: Schubert, Manners, and Newkome)

Abstract: Polymer 6, $\left(\left[\text { trans }-\mathrm{Pt}\left(\mathrm{PBu}_{3}\right)_{2}(\mathrm{C} \equiv \mathrm{C})_{2}\right]-\left[\operatorname{Ir}(\mathrm{dFMeppy})_{2}\left(\mathrm{~N}^{\wedge} \mathrm{N}\right)\right]\left(\mathrm{PF}_{6}\right)\right)_{\mathrm{n}},(([\mathrm{Pt}]-$ $\left.[\operatorname{Ir}]\left(\mathrm{PF}_{6}\right)\right)_{\mathrm{n}} ; \mathrm{N}^{\wedge} \mathrm{N}=5,5^{\prime}$-disubstituted-2,2'-bipyridyl; dFMeppy = 2-(2,4-difluorophenyl)-5-methylpyridine) has been prepared along with model compounds. These complexes were investigated by absorption and emission spectroscopy and their photophysical and electrochemical properties were measured and compared with their corresponding non-fluorinated complexes. Density functional theory (DFT) and timedependent DFT computations corroborate the nature of the excited state as being a hybrid between the metal-to-ligand charge transfer $\left({ }^{1,3} \mathrm{MLCT}\right)$ for the trans$\mathrm{Pt}\left(\mathrm{PBu}_{3}\right)_{2}(\mathrm{C} \equiv \mathrm{CAr})_{2}$ unit, [Pt] and the metal-to-ligand/ligand-to-ligand' charge transfer $\left({ }^{1,3} \mathrm{ML}{ }^{\prime} \mathrm{CT} / \mathrm{LL}{ }^{\prime} \mathrm{CT}\right)$ for [Ir] with $\mathrm{L}=$ hybrid charge transfer dFMeppy. Overall, the fluorination of the phenylpyridine group expectedly does not change the nature of the excited state but desirably induces a small blue shift of the absorption and emission bands along a slight decrease in emission quantum yields and lifetimes.

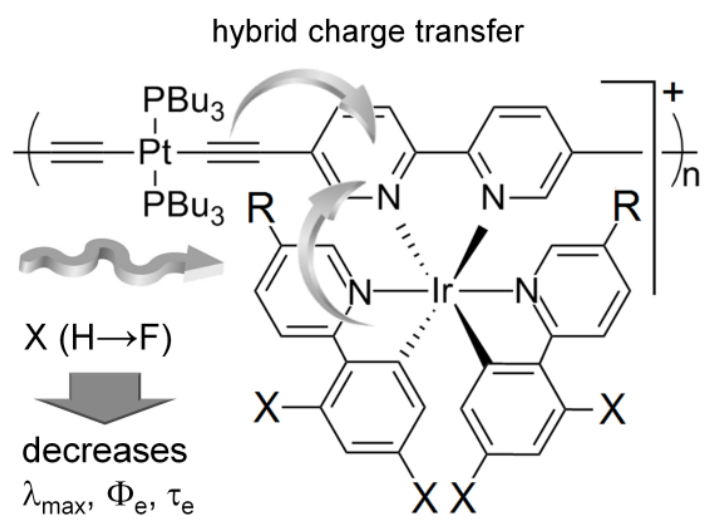


Introduction. The ortho-metallated motif $\left[\operatorname{Ir}(\mathrm{ppy})_{2}\left(\mathrm{~N}^{\wedge} \mathrm{N}\right)\right]^{+}(\mathrm{ppyH}=2$-phenylpyridine; $\mathrm{N}^{\wedge} \mathrm{N}=$ neutral diimine ligand), [Ir], remains a chromophore of choice for electro-luminescence applications, notably for organic light emitting diodes (OLEDs), light-emitting electrochemical cells (LEECs). ${ }^{[1,2]}$ Indeed, literature designs are notably rich in structure modifications $v s$ properties of the materials. The use of this motif embedded inside the skeleton of an organic conjugated polymer, dendrimer or utilized as a pendant group, instead of the common complex dopant into an organic polymer, showed a clear interest in the past decade. ${ }^{[3]}$ In the field of conjugated organometallic polymer, we recently reported polymer 12 as a bimetallic design (Fig. 1). ${ }^{[4]}$

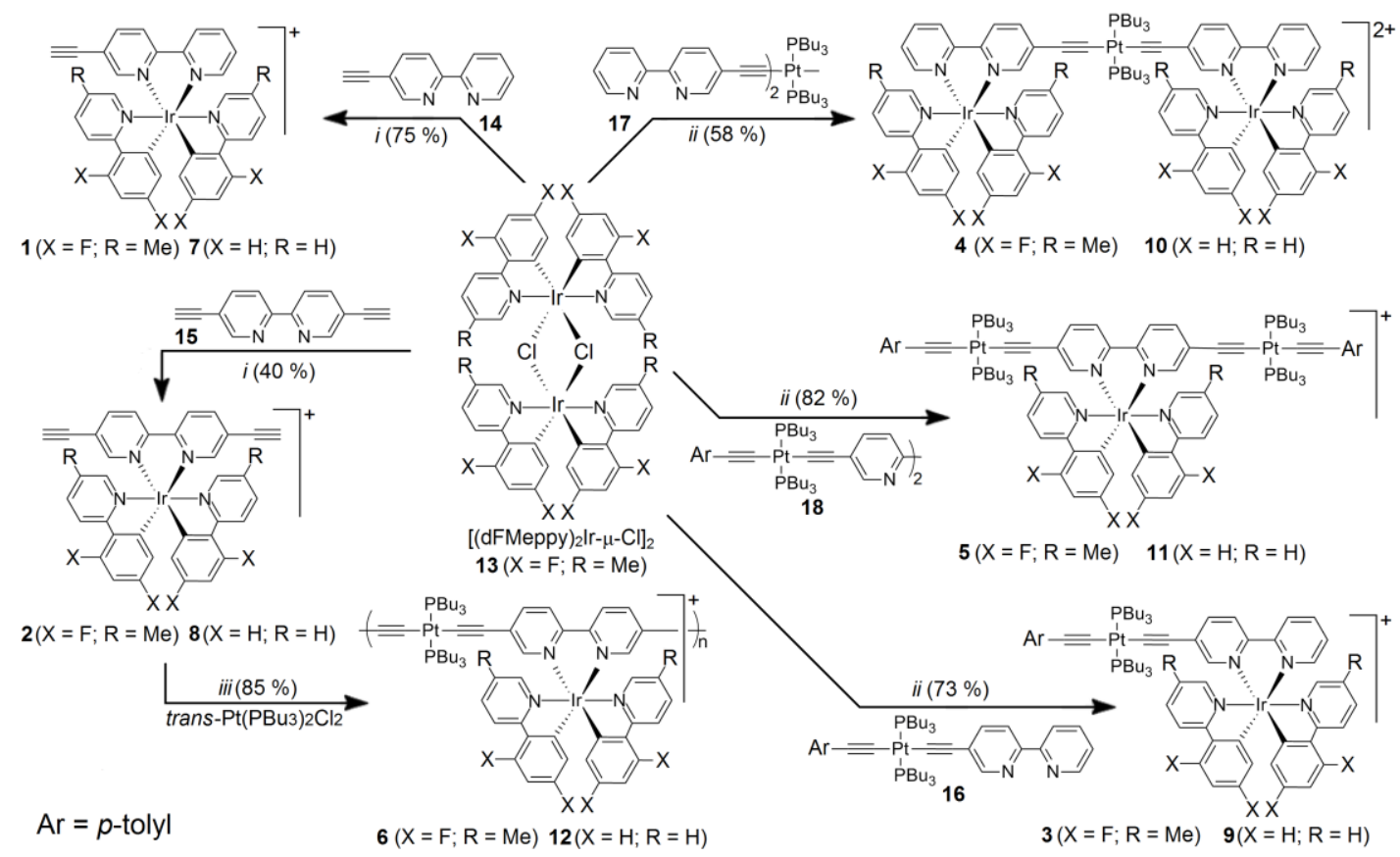

Figure 1. Syntheses of compounds 1-6 (yields in brackets) along with the structural comparison with their previously reported non-fluorinated homologues 7-12: i) $\mathrm{CH}_{2} \mathrm{Cl}_{2}: \mathrm{CH}_{3} \mathrm{OH}, 60{ }^{\circ} \mathrm{C}$; (b) $\mathrm{NH}_{4} \mathrm{PF}_{6}$ (aq.) $i$ i) $\mathrm{CH}_{2} \mathrm{Cl}_{2}: \mathrm{CH}_{3} \mathrm{OH}, 60{ }^{\circ} \mathrm{C}$; (b) $\mathrm{NH}_{4} \mathrm{PF}_{6}$ (aq.) $\mathrm{CH}_{2} \mathrm{Cl}_{2}, i \mathrm{Pr}_{2} \mathrm{NH}$, CuI. All counter anions are $\left(\mathrm{PF}_{6}\right)^{-}$.

12 exhibits similar photophysical traits as for the model compounds $\mathbf{8}$ and $\mathbf{1 1}$ making it potentially useful for photonic applications. One interesting aspect in a fundamental point of view is the nature of its excited state, which turns out to be a hybrid between the metal-to-ligand charge transfer $\left({ }^{1,3} \mathrm{MLCT}\right)$ for the trans- $\mathrm{Pt}\left(\mathrm{PBu}_{3}\right)_{2}(\mathrm{C} \equiv \mathrm{CAr})_{2}$ unit, [Pt] and the metal-to-ligand/ligand-to-ligand' charge transfer $\left({ }^{1,3} \mathrm{ML}{ }^{\prime} \mathrm{CT} / \mathrm{LL}{ }^{\prime} \mathrm{CT}\right)$ for [Ir] with $\mathrm{L}=$ ppy. ${ }^{[5-7]}$ However, the linking of two or more conjugated units together almost systematically led to a red-shifting of the emission band. This common phenomenon is not necessarily desired for the design of blue emitting devices. Therefore modulation of the photonic properties in such materials should benefit from 
appropriate substitution. We now report the effect of fluorination of polymer 12, providing polymer 6. The combination of the anticipated strong blue shift of the absorption and emission bands due to fluorination, and the red-shift due to conjugation with $[\mathbf{P t}]$ along the polymer backbone, leads to a small blue shift (only $\sim 10 \mathrm{~nm}$ ) of the spectral features, hence providing the desired effect.

Results and Discussion. The model complexes 1-5 and polymer 6 were synthesized in reasonable yields from dimer $13\left[(\mathrm{dFMeppy})_{2} \mathrm{Ir}-\mu-\mathrm{Cl}\right]_{2}$ following procedures used for the corresponding non-fluorinated derivatives. ${ }^{[4-7]}$ Their syntheses and characterization are placed in the Experimental Section (SI). The absorption and emission spectra of 36 exhibit the characteristic signature expected for the [Ir] motif (Figure 2). ${ }^{[4-8]}$ The spectroscopic and photophysical data of 1-6 are compared to those for 7-12 in Table 1.

Table 1. Comparison of the spectral and photophysical data of 1-6 vs 7-12. , $^{\mathrm{a}}$

\begin{tabular}{|c|c|c|c|c|c|c|}
\hline & $\begin{array}{l}\text { Abs. }(\mathrm{nm}) 298 \mathrm{~K} \\
{\left[\varepsilon\left(\mathrm{x} 10^{4} \mathrm{M}^{-1} \mathrm{~cm}^{-1}\right)\right]}\end{array}$ & $\begin{array}{c}\lambda_{\max }(\mathrm{nm}) \\
77 \mathrm{~K}\end{array}$ & $\begin{array}{l}\lambda_{\max }(\mathrm{nm}) \\
298 \mathrm{~K} \\
\end{array}$ & $\begin{array}{c}\Phi_{\mathrm{e}} \\
(\%)\end{array}$ & $\begin{array}{c}\tau_{\mathrm{e}}(\mu \mathrm{s}) \\
77 \mathrm{~K}\end{array}$ & $\begin{array}{l}\tau_{\mathrm{e}}(\mu \mathrm{s}) \\
298 \mathrm{~K} \\
\end{array}$ \\
\hline 1 & $\begin{array}{l}250[5.2] ; 265[5.2] ; 315[3.1] ; 330[2.4] ; 365 \\
{[0.8] ; 425[0.1]}\end{array}$ & 490 & 561 & 5.8 & 4.46 & 0.51 \\
\hline 2 & $\begin{array}{l}255[3.8] ; 265[3.6] ; 290[3.0] ; 315[2.5] ; 330 \\
{[2.5] ; 345[2.6] ; 385[0.4] ; 450[0.1]}\end{array}$ & 523 & 575 & 2.5 & 4.40 & 0.13 \\
\hline 3 & 255 [5.8]; $310[3.2] ; 395[2.4]$ & 556 & 614 & 11.4 & 14.3 & 4.57 \\
\hline 4 & $\begin{array}{l}250[6.3] ; 265[4.2] ; 310[3.4], 350[2.4], 400 \\
{[4.8]}\end{array}$ & 544 & 567 & 11.6 & 10.4 & 2.51 \\
\hline 5 & $\begin{array}{l}255 \text { [5.6]; } 310[3.3] ; 350[2.1] ; 425[3.8] ; 450 \\
{[3.9]}\end{array}$ & 593 & 632 & 1.9 & 6.11 & 1.93 \\
\hline 6 & $\begin{array}{l}250 \text { [3.9]; } 260 \text { [3.2]; } 315 \text { [1.2], } 415 \text { [1.2], } 485 \\
{[0.1]}\end{array}$ & $\begin{array}{l}547 \\
592 \\
640\end{array}$ & 628 & 1.0 & $\begin{array}{l}4.81 \\
4.22\end{array}$ & 0.8 \\
\hline 7 & $\begin{array}{l}265[2.3] ; 310[1.0] ; 325[0.9] ; 380[0.2] ; 450 \\
{[0.1]}\end{array}$ & 536 & 623 & 8.5 & 4.12 & 0.16 \\
\hline 8 & 250 [4.2]; 280 [3.3]; 315 [2.3]; 370 [0.8] & 558 & 638 & 1.6 & 2.65 & 0.09 \\
\hline 9 & 260 [3.7]; 315 [2.0]; 390 [1.9] & 557 & 611 & 8.3 & 3.4 & 0.72 \\
\hline 10 & $\begin{array}{l}260[6.8] ; 300[4.1] ; 350[4.0] ; 370[4.0], 460 \\
{[0.2]}\end{array}$ & 547 & 595 & 31.9 & 11 & 2.9 \\
\hline 11 & 255 [9.8]; 315 [5.1]; 415 [7.9]; 435 [9.1] & $\begin{array}{l}550 \\
595 \\
651\end{array}$ & $\begin{array}{l}560 \\
613 \\
663\end{array}$ & 3.3 & 5.9 & 2.3 \\
\hline 12 & 250 [0.3]; $280[0.2] ; 340[0.1] ; 435[0.2]$ & $\begin{array}{l}558 \\
596 \\
654\end{array}$ & $\begin{array}{l}555 \\
617 \\
655\end{array}$ & 2.6 & $\begin{array}{l}5.7 \\
3.3\end{array}$ & 2.5 \\
\hline
\end{tabular}

a) The data for 7-12 are from references [4-6] and for 1 from reference [7]. b) The uncertainties on $\lambda_{\max }= \pm 2 \mathrm{~nm}$, on $\Phi_{\mathrm{e}}=10 \%$, and on $\tau_{\mathrm{e}} \approx 5 \%$. For 6,11 and 12, the $\tau_{\mathrm{e}}$ 's were measured at one, two or three different wavelengths. 

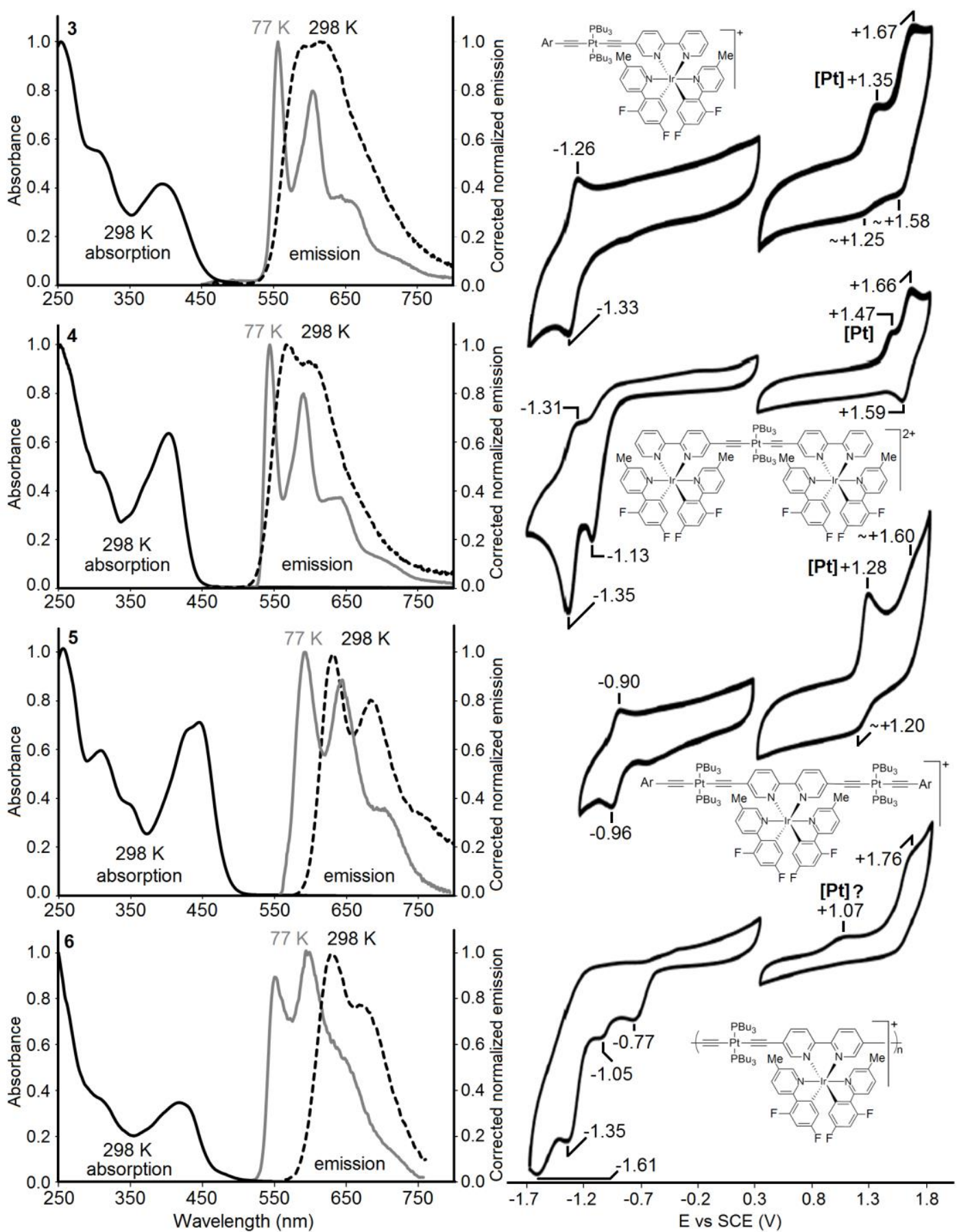

Figure 2. Left: absorption (black -) and emission (grey -, 77; black ---, $298 \mathrm{~K}$ ) of 36 in 2MeTHF at $298 \mathrm{~K}$. Right: cyclic voltammograms of 3-6 in degassed ACN at 298 $\mathrm{K}$. Scan rate $=200 \mathrm{mV} / \mathrm{s}$ with $0.1 \mathrm{M} n-\mathrm{Bu}_{4} \mathrm{NPF}_{6}$ as the supporting electrolyte. All waves are associated with [Ir] except those labelled [Pt] (i.e. trans- $\left.\mathrm{Pt}\left(\mathrm{PBu}_{3}\right)_{2}(\operatorname{aryl})_{2}\right)$.

Spectroscopically, two main observations are striking (Table 1). First, a significant blue shift of the absorption and emission bands is noted upon fluorination of the complexes when comparing $\mathbf{1}$ vs $\mathbf{7}$ and $\mathbf{2}$ vs $\mathbf{8}$. This behavior is fully consistent with the ML'CT/LL'CT nature of the excited states where the F-atom is withdrawing 
electronic density on the ppy ligand. Second, this blue shift is smaller for the polymers (6 vs 12). This attenuation of F-inductive effect is explained by the hybrid nature of the excited state between the $\mathrm{C} \equiv \mathrm{C}$-linked $[\mathbf{P t}]$ and $[\mathbf{I r}]$ units that contributes to spread the electron withdrawing pull over a larger segment of the polymer. In a photophysical point of view, the $\Phi_{\mathrm{e}}$ and $\tau_{\mathrm{e}}$ data for 1-6 are similar or at least in the same order of magnitude as those for 7-12. However, these parameters are globally smaller for the 1-6 compared to 7-12 (including polymer 6 vs 12) indicating that the nonradiative rate constant, $\mathrm{k}_{\mathrm{nr}}$, is larger for the fluorinated species.
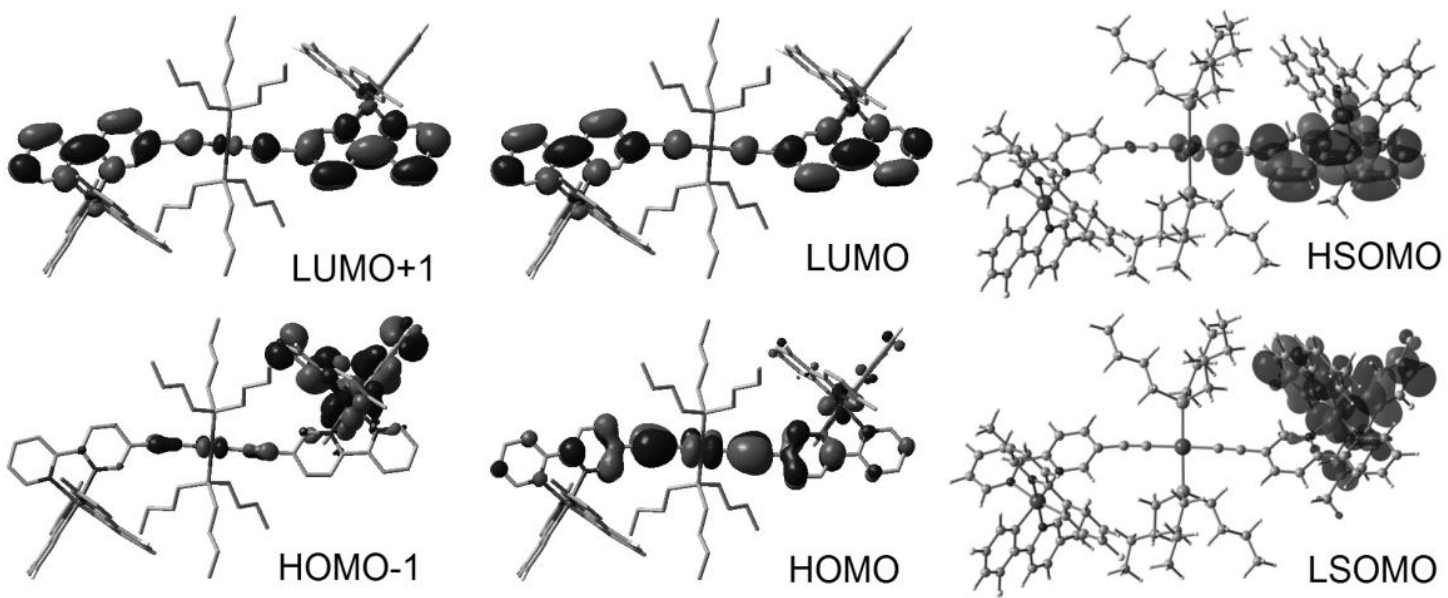

Figure. 3. MO drawings of the frontier orbitals of the model 4 (left) and the HSOMO and LSOMO (right). The detail of the DFT and TDDFT calculations are in the SI.

The nature of the $S_{1} / T_{1}$ excited states was corroborated by DFT calculations (Figure 3 ). Indeed for model 4, the HOMO is composed of the $\pi$-system centered on the [Pt] unit with minor atomic contributions of the bipyridine fragments (bpy). The HOMO-1 and -2 are composed of atomic components of the dFMeppy $\pi$-systems with a minor contribution of the central [Pt] unit. The LUMO and LUMO+1 exhibit contributions from the $\mathrm{N}^{\wedge} \mathrm{N} \pi *$-systems, with a minor atomic component located on [Pt]. The TDDFT computations for $\mathbf{4}$ predict that the two lowest energy singlet-singlet electronic transitions are placed at $465.8(\mathrm{f}=0.0188)$ and $463.5 \mathrm{~nm}(\mathrm{f}=0.003)$ with weak oscillator strengths (f). The positions of these $0-0$ peaks corroborate well with the experimental spectrum where a weak tail extends all the way to $465 \mathrm{~nm}$ (Figure 2). These two transitions are respectively composed of HOMO-1 $\rightarrow$ LUMO (45\%), HOMO$1 \rightarrow \mathrm{LUMO}+1(35 \%), \mathrm{HOMO} \rightarrow \mathrm{LUMO}(12 \%)$ and HOMO-2 $\rightarrow$ LUMO $(67 \%), \mathrm{HOMO}-$ $2 \rightarrow$ LUMO+1 $(31 \%)$, hence confirming the hybrid nature of the singlet excited states discussed above. The calculated difference in total energy between the $\mathrm{S}_{0}$ and $\mathrm{T}_{1}$ states 
is $2.377 \mathrm{eV}$, which places the triplet state at $522 \mathrm{~nm}$. This value compares favorably to the one observed at $77 \mathrm{~K}$ (i.e. 544 for 4 and $547 \mathrm{~nm}$ for $\mathbf{6}$ ). The computed highest and lowest semi-occupied MO's (respectively HSOMO and LSOMO) exhibit atomic contributions mostly located in the $\mathrm{N}^{\wedge} \mathrm{N}$ and dFMeppy $\pi$-systems, respectively, inferring that the nature of the excited state is (ML'CT/LL'CT) of the [Ir] chromophore. Overall, these computations indicate that presented substitution pattern expectedly does not affect the nature of the $S_{1}$ and $T_{1}$ states for this type of chromophore, i.e. $\left([\mathbf{I r}]-[\mathbf{P t}]^{+}\right)_{n}$.

The cyclic voltammograms, CV, of 3-6 are presented in Figure 2 and the peak positions are placed in Table 2 (when both cathodic and anodic waves are observable, only the averaged peak positions are reported in this table for simplicity). The assignment for each waves indicated in the figure caption is based on previous CV analysis for $\mathbf{1}$ (and its dimer) and trans- $\mathrm{C}_{6} \mathrm{H}_{5} \mathrm{C} \equiv \mathrm{C}-\mathrm{PtL}_{2}-\mathrm{C} \equiv \mathrm{CC}_{6} \mathrm{H}_{5}$ and its derivatives ( $\mathrm{L}=$ phosphine). ${ }^{[7,9]}$ The fact that $\mathrm{E}_{1 / 2 \mathrm{red}}(\mathbf{1})<\mathrm{E}_{1 / 2 \mathrm{red}}(\mathbf{7})$ and $\mathrm{E}_{1 / 2 \mathrm{xx}}(\mathbf{1})>\mathrm{E}_{1 / 20 \mathrm{xx}}(\mathbf{7})$ is consistent with the expected withdrawing effect of the fluorine atoms. When one electron rich [Pt] unit is conjugated to the [Ir] one, this effect is almost completely cancelled $\left(\mathrm{E}_{1 / 2 \mathrm{red}}(\mathbf{3}) \sim\right.$ $\mathrm{E}_{1 / 2 \text { red }}(\mathbf{9})$ and $\left.\mathrm{E}_{1 / 20 \mathrm{x}}(\mathbf{3}) \sim \mathrm{E}_{1 / 2 \mathrm{x}}(\mathbf{9})\right)$, which is exactly the effect sought. However, the peak positions are dependent upon the relative number of $[\mathbf{P t}]$ and $[\mathbf{I r}]$ units for the short oligomers. Indeed, $\mathrm{E}_{1 / 2 \text { red }}(\mathbf{4})<\mathrm{E}_{1 / 2 \mathrm{red}}(\mathbf{1 0})$ and $\mathrm{E}_{1 / 2 \mathrm{xx}}(\mathbf{4})>\mathrm{E}_{1 / 2 \mathrm{ox}}(\mathbf{1 0})$ (one [Pt] for two [Ir]) again witnessing the withdrawing effect for the fluorine, and $\mathrm{E}_{1 / 2 \mathrm{red}}(\mathbf{5})>\mathrm{E}_{1 / 2 \text { red }}(\mathbf{1 1})$ and $\mathrm{E}_{1 / 20 \mathrm{x}}(\mathbf{5})<\mathrm{E}_{1 / 20 \mathrm{x}}(\mathbf{1 1})$ (two [Pt] for one [Ir]), which is consistent with the donating ability of the conjugated rich [Pt] unit. Based on these models, one readily suspects that for polymers wherein the number of $[\mathbf{P t}]$ and $[\mathbf{I r}]$ units being about the same, an approximate cancellation of the withdrawing and donating effects should be observed. This is in fact not the case. In comparison with the short oligomers, both polymers turned out to be both easier to oxidize and to reduce (i.e. lower positive and negative potentials). This property is fully consistent with the presence of an extended conjugation. However, the drawback is that all waves are either electrochemically irreversible or chemically irreversible making this sought analysis unreliable. Indeed, the data do not explain why polymer $\mathbf{6}$ is both harder to oxidize and to reduce than polymer 12, and why the potential difference between $\left|\mathrm{E}_{1 / 20 \mathrm{x}}\right|$ and $\left|\mathrm{E}_{1 / 2 \mathrm{red}}\right|, \Delta \mathrm{E}$, is significantly smaller for $\mathbf{1 2}$ than for $\mathbf{6}$ and all the model complexes. 
Table 2. Electrochemical data for 1, 3-6, 7, 9-12

\begin{tabular}{cccccccc}
\hline & $\mathrm{E}_{1 / 20 \mathrm{ox}}$ & $\Delta \mathrm{E}$ & $\mathrm{E}_{1 / 2 \mathrm{red}}$ & & $\mathrm{E}_{1 / 20 \mathrm{ax}}$ & $\Delta \mathrm{E}$ & $\mathrm{E}_{1 / 2 \mathrm{red}}$ \\
\hline $\mathbf{1}$ & $1.58^{\mathrm{a}}$ & 2.71 & $-1.13^{\mathrm{a}}$ & $\mathbf{7}$ & $1.27^{\mathrm{a}}$ & 2.48 & $-1.21^{\mathrm{a}}$ \\
$\mathbf{3}$ & $1.30^{\mathrm{c}}$ & 2.60 & $-1.30^{\mathrm{a}}$ & $\mathbf{9}$ & $1.34^{\mathrm{a}}$ & 2.68 & $-1.34^{\mathrm{a}}$ \\
& $1.63^{\mathrm{b}}$ & & & & $1.60^{\mathrm{a}}$ & & \\
$\mathbf{4}$ & $1.47^{\mathrm{c}}$ & 2.60 & $-1.13^{\mathrm{c}}$ & $\mathbf{1 0}$ & $1.31^{\mathrm{a}}$ & 2.67 & $-1.36^{\mathrm{a}}$ \\
& $1.63^{\mathrm{b}}$ & & $-1.33^{\mathrm{c}}$ & & & & \\
$\mathbf{5}$ & $1.24^{\mathrm{c}}$ & 2.17 & $-0.93^{\mathrm{a}}$ & $\mathbf{1 1}$ & $1.36^{\mathrm{c}}$ & 2.71 & $-1.35^{\mathrm{c}}$ \\
& $\sim$ & & & & & & \\
$\mathbf{6}$ & $1.70^{\mathrm{c}}$ & & & & & & \\
& $1.07^{\mathrm{c}}$ & 1.84 & $-0.77^{\mathrm{c}}$ & $\mathbf{1 2}$ & $0.71^{\mathrm{c}}$ & 1.11 & $-0.40^{\mathrm{c}}$ \\
& & & $-1.05^{\mathrm{c}}$ & & $1.22^{\mathrm{c}}$ & - & $-0.77^{\mathrm{c}}$ \\
& & & $-1.35^{\mathrm{c}}$ & & $1.34^{\mathrm{c}}$ & - & $-0.93^{\mathrm{b}}$ \\
& & & $-1.61^{\mathrm{c}}$ & & & - & $-1.29^{\mathrm{b}}$ \\
\hline
\end{tabular}

All in $\mathrm{V} v s$ SCE, the data for 1 are from reference [7] and for 7, 9-12 are from reference [6]; $a=$ e.r. (electrochemically reversible), $b=$ c.r. (chemically reversible), $c$ $=\operatorname{ir}$ (irreversible), $\Delta \mathrm{E}=\left|\mathrm{E}_{1 / 2 \mathrm{ox}}\right|+\left|\mathrm{E}_{1 / 2 \mathrm{red}}\right|$ ).

Conclusion. The hybrid nature of the conjugated $\left([\mathbf{I r}]-[\mathbf{P t}]^{+}\right)_{\mathrm{n}}$ polymers in their excited state contributes to modulate their desired electronic properties via simple inductive effects. Indeed, from an electronic and spectroscopic standpoint, the withdrawing pull of the fluorine atoms on the $\mathrm{C}^{\wedge} \mathrm{N}$ ligands of [Ir] compensates for the red-shifting effect of the conjugated [Pt] unit within the chain on the absorption and emission bands of the polymers was successful, i.e. within $\sim 10 \mathrm{~nm}$. Including the electron donating push of the [Pt] unit, these three individual effects (electron withdrawing and donating effects, along with conjugation) could be readily observed by cyclic voltammetry measurements using the model compounds in comparison with the polymers. This strategy, which is particularly convenient, simple and predictable, appears as a reliable approach for the future design of conjugated [Ir]-containing polymers.

Experimental Section: see Supporting Information (SI).

Acknowledgements. This research was supported by the Natural Sciences and Engineering Research Council of Canada (NSERC).

\section{References}

[1] a) K. P. S. Zanoni, B. K. Kariyazaki, A. Ito, M. K. Brennaman, T. J. Meyer, I.

Murakami, Y. Neyde, Inorg.Chem., 2014, 53, 4089; b) G. E. Schneider, A. Pertegas, E. 
C. Constable, C. E. Housecroft, N. Hostettler, C. D. Morris, J. A. Zampese, J. A., H. J. Bolink, J. M. Junquera-Hernandez, E. Orti, M. Sessolo, J. Mat. Chem. C: Mat. Opt. Elec. Devices, 2014, 2, 7047; c) R. Srivastava, L. R. Joshi, Phys. Chem. Chem. Phys. 2014, 16, 17284; d) P. Li, G-G. Shan, H-T. Cao, D-X. Zhu, Z-M. Su, R. Jitchati, M. R. Bryce, Eur. J. Inorg. Chem., 2014, 2014, 2376; e) N. Darmawan, C-H. Yang, M. Mauro, R. Froehlich, L. De Cola, C-H. Chang, Z-J. Wu, C-W. Tai, J. Mat. Chem. C: Mat. Opt. Elec. Devices, 2014, 2, 2569; f) H. Tang, L. Wei, J. Wang, Y. Li, H. Wu, W. Yang, Y. Cao, Syn. Met., 2014, 187, 209; g) T. Akatsuka, C. Roldan-Carmona, E. Orti, H. J. Bolink, Adv. Mat., 2014, 26, 770; h) K. Hasan, L. Donato, Y. Shen, J. D. Slinker, E. Zysman-Colman, Dalton Trans., 2014, 43, 13672; i) E. C. Constable, C. D. Ertl, C. E. Housecroft, J. A. Zampese, Dalton Trans,. 2014, 43, 5343; j) G. E. Schneider, H. J. Bolink, E. C. Constable, C. D. Ertl, C. E. Housecroft, A. Pertegas, J. A. Zampese, A. Kanitz, F. Kessler, S. B. Meier, Dalton Trans., 2014, 43, 1961; k) E. C. Constable, C. E. Housecroft, P. Kopecky, C. J. Martin, I. A. Wright, J. A. Zampese, H. J. Bolink, A. Pertegas, Dalton Trans., 2014, 42, 8086; 1) S. Evariste, M. Sandroni, T. W. Rees, C. Roldán-Carmona, L. Gil-Escrig, H. J. Bolink, E. Baranoff, E. Zysman-Colman J. Mater. Chem. C, 2014, 2, 5793.

[2] a) H. J. Park, J. N. Kim, H-J. Yoo, K-R. Wee, S. O. Kang, D. W. Cho, U. C. Yoon, J. Org. Chem., 2013, 78, 12281; b) L. J. Rono, H. G. Yayla, D. Y. Wang, M. F. Armstrong, R. R. Knowles, J. Am. Chem. Soc., 2013, 135, 17735; c) F. Dumur, M. Lepeltier, B. Graff, E. Contal, G. Wantz, J. Lalevee, C. R. Mayer, D. Bertin, D. Gigmes, Syn. Met, 2013, 182, 13; d) K. Mori, Y. Kubota, H. Yamashita, Chem. Asian J., 2013, 8, 3207; e) S. Lee, S-O. Kim, H. Shin, H-J. Yun, K. Yang, S-K. Kwon, J-J. Kim, Y-H. Kim, J. Am. Chem. Soc., 2013, 135, 14321; f) D. Tordera, J. J. SerranoPerez, A. Pertegas, E. Orti, H. J. Bolink, E. Baranoff, Md. K. Nazeeruddin, J. Frey, Chem. Mater., 2013, 25, 3391; g) H. J. Park, J. N. Kim, H-J. Yoo, K-R. Wee, S. O. Kang, D. W. Cho, U. C. Yoon, J. Org. Chem., 2013, 78, 8054; h) H-H. Chou, Y-K. Li, Y-H. Chen, C-C. Chang, C-Y. Liao, C-H. Cheng, ACS Appl. Mater. Interfaces, 2013, 5, 6168; i) Y. Shen, D. D. Kuddes, C. A. Naquin, T. W. Hesterberg, C. Kusmierz, B. J. Holliday, J. D. Slinker, Appl. Phys. Lett. 2013, 102, 203305/1; j) T. Hu, L. Duan, J. Qiao, L. He, D. Zhang, L. Wang, Y. Qiu, Syn. Met, 2013, 163, 33; k) Y. Zhou, S. Han, G. Zhou, W-Y Wong, V. A. L. Roy, Appl. Phys. Lett., 2013, 102, 083301; 1) N. M. Shavaleev, R. Scopelliti, M. Grätzel, M. K. Nazeeruddin, A. Pertegas, C. 
Roldan-Carmona, D. Tordera, H. J, Bolink, J. Mat. Chem. C: Mat. Opt. Elec. Devices, 2013, 1, 2241; m) M. Sessolo, D. Tordera, Daniel; H. J. Bolink, ACS Appl. Mater. Interfaces, 2013, 5, 630; n) S. van Reenen, T. Akatsuka, D. Tordera, Daniel, M. Kemerink, H. J. Bolink, J. Am. Chem. Soc., 2013, 135, 886; o) S. B. Meier, S. van Reenen, B. Lefevre, D. Hartmann, H. J. Bolink, A. Winnacker, W. Sarfert, M. Kemerink, Adv. Funct. Mater, 2013, 23, 3531; p) J. M. Fernández-Hernández, S. Ladouceur, Y. Shen, A. Iordache, X. Wang, L. Donato, S. Gallagher-Duval, M. de Anda Villa, J. D. Slinker, L. De Cola, E. Zysman-Colman J. Mater. Chem. C, 2013, 1, 7440; q) C.-L.; Ho, W.-Y. Wong, Coord. Chem. Rev. 2013, 257, 1614; r) Y. Zhou, S. Han, G. Zhou, W.-Y. Wong, V. A. L. Roy Appl. Phys. Lett. 2013, 102, 083301/1. [3] a) T. Guo, L. Yu, B. Zhao, Y. Li, Y. Tao, W. Yang, Q. Hou, H. Wu, Y. Cao, Macromol. Chem. Phys., 2012, 213, 820; b) T. Guo, R. Guan, J. Zou, J. Liu, L. Ying, W Yang, H. Wu, Y. Cao, Polym. Chem., 2011, 2, 2193; c) F. Dumur, Y.

Guillaneuf, A. Guerlin, G. Wantz, D. Bertin, F. Miomandre, G. Clavier, D. Gigmes, C. R. Mayer, Macromol. Chem. Phys. 2011, 212, 1616; d) J. W. Levell, J. P. Gunning, P. L. Burn, J. Robertson, I. D. W. Samuel, Org. Electron, 2010, 11, 1561; e) T. W. Hesterberg, X. Yang, B. Holliday, J. Polyhedron, 2010, 29, 110; f) B. Liang, Y. Xu, Z. Chen, J. Peng, Y. Cao, Synthetic Metals, 2009, 159, 1876; g) B. Liang, L. Wang, Y. Xu, H. Shi, Y. Cao, Adv. Funct. Mater., 2007, 17, 3580; h) H. Zhen, J. Luo, W. Yang, Q. Chen, L. Ying, J. Zou, H. Wu, Y. Cao, J. Mater. Chem., 2007, 17, 2824; i) S-J. Liu, Q. Zhao, Y. Deng, Y-J. Xia, J. Lin, Q-L. Fan, L-H. Wang, W. Huang, J. Phys. Chem. C. 2007, 111, 1166.

[4] A. M. Soliman, D. Fortin, E. Zysman-Colman, P. D. Harvey, Macromol. Rapid Commun., 2012, 33, 522.

[5] A. M. Soliman, D. Fortin, P. D. Harvey, E. Zysman-Colman, Chem. Commun., 2012, 48, 1120 .

[6] A. M. Soliman, D. Fortin, E. Zysman-Colman, P. D. Harvey, Chem. Commun., 2012, 48, 6271 .

[7] A. M. Soliman, D. Fortin, P. D. Harvey, E. Zysman-Colman, Dalton Trans., 2012, $41,9382$.

[8] G. Zhou, Y. He, B. Yao, J. Dang, W.-Y. Wong; Z. Xie, X. Zhao, L. Wang, Chem. Asian J. 2010, 5, 2405.

[9] T. Kenny, S. Lamare, S. M. Aly, D. Fortin, G. Brisard, P. D. Harvey Inorg. Chem. 2012, 51, 13081. 